Trinity University

Digital Commons @ Trinity

Psychology Faculty Research

Psychology Department

2021

\title{
Binge Eating Among Older Women: Prevalence Rates and Health Correlates Across Three Independent Samples
}

Salomé A. Wilfred

Carolyn Black Becker

Trinity University, cbecker@trinity.edu

K. E. Kanzler

N. Musi

S. E. Espinoza

See next page for additional authors

Follow this and additional works at: https://digitalcommons.trinity.edu/psych_faculty

Part of the Psychology Commons

Publication Details

Journal of Eating Disorders

\section{Repository Citation}

Wilfred, S. A., Becker, C. B., Kanzler, K. E., Musi, N., Espinoza, S. E., \& Kilpela, L. S. (2021). Binge eating among older women: Prevalence rates and health correlates across three independent samples. Journal of Eating Disorders, 9, Article 132. http://doi.org/10.1186/s40337-021-00484-8

This Article is brought to you for free and open access by the Psychology Department at Digital Commons @ Trinity. It has been accepted for inclusion in Psychology Faculty Research by an authorized administrator of Digital Commons@ Trinity. For more information, please contact jcostanz@trinity.edu. 


\section{Authors}

Salomé A. Wilfred, Carolyn Black Becker, K. E. Kanzler, N. Musi, S. E. Espinoza, and Lisa S. Kilpela 


\title{
Binge eating among older women: prevalence rates and health correlates across three independent samples
}

\author{
Salomé Adelia Wilfred', Carolyn Black Becker ${ }^{2}$, Kathryn E. Kanzler ${ }^{3}$, Nicolas Musi ${ }^{4,5}$, Sara E. Espinoza ${ }^{4,5}$ and \\ Lisa Smith Kilpela ${ }^{3,4^{*}}$
}

\begin{abstract}
Background: Emerging research indicates that binge eating ( $\mathrm{BE}$; consuming unusually large amounts of food in one siting while feeling a loss of control) is prevalent among older women. Yet, health correlates of BE in older adult populations are poorly understood. The original study aimed to investigate BE prevalence, frequency, and health correlates in a sample of older adult women. Based on results from this first study, we then sought to replicate findings in two additional samples of older adult women from separate studies.
\end{abstract}

Method: Using self-reported frequencies of BE from three separate samples of older women with very different demographics, we compared BE prevalence, frequency, and health correlates among older women. Study $1(N=185)$ includes data collected online (86\% White; 59\% overweight/obese status). Study 2 ( $N=64)$ was conducted in person at a local food pantry (65\% Hispanic; 47\% household income $<\$ 10,000 /$ year). Study $3(N=100)$ comprises data collected online (72\% White; 50\% Masters/Doctoral Degree).

Results: Per DSM-5 frequency criterion of BE at least weekly, we found prevalence rates ranging from 19 to $26 \%$ across the three samples. Correlates of BE frequency included elevated negative mood, worry, BMI, and less nutritious food consumption.

Conclusions: Across three very different samples in terms of race/ethnicity, education, food security status, measurements, and sampling methodology, we found fairly consistent rates of self-reported BE at least weekly (19-26\%). Results suggest that BE is related to negative health indices among older women and support the need for more research in this population.

Keywords: Aging, Binge eating, Women's health

\section{Plain English summary}

Historically viewed as problems of youth, eating disorders are understudied in older women. Yet, disordered eating, especially binge eating (BE; eating an unusually large amount of food with loss of control), appears to be more prevalent among older women than previously thought.

\footnotetext{
*Correspondence: kilpela@uthscsa.edu

${ }^{3}$ ReACH Center, UT Health San Antonio, San Antonio, TX, USA

Full list of author information is available at the end of the article
}

Importantly, $\mathrm{BE}$ is associated with various health problems in the general population, but less is known about health outcomes related to $\mathrm{BE}$ in older populations. We compared prevalence rates of weekly $\mathrm{BE}$ measured in three separate samples of older women, as well as various health and wellness indices. We found fairly consistent rates of BE at least weekly (19-26\%) across the three samples, and that $\mathrm{BE}$ frequency was related to negative health outcomes among older adult women. There is still much to be learned about $\mathrm{BE}$ among older adult populations. original author(s) and the source, provide a link to the Creative Commons licence, and indicate if changes were made. The images or other third party material in this article are included in the article's Creative Commons licence, unless indicated otherwise in a credit line to the material. If material is not included in the article's Creative Commons licence and your intended use is not permitted by statutory regulation or exceeds the permitted use, you will need to obtain permission directly from the copyright holder. To view a copy of this licence, visit http://creativecommons.org/licenses/by/4.0/. The Creative Commons Public Domain Dedication waiver (http://creativeco mmons.org/publicdomain/zero/1.0/) applies to the data made available in this article, unless otherwise stated in a credit line to the data. 
Future research is needed to better understand how specific age-related experiences may comprise risk factors for disordered eating among older women.

\section{Background}

Nutrition pathology can significantly interfere with healthy aging. One form of nutrition pathology is disordered eating. Although clinical eating disorders and subclinical disordered eating are commonly viewed as problems of youth, emerging research indicates that older women indeed struggle with the spectrum of disordered eating $[1,2]$. One of the most common forms of disordered eating among midlife and older women appears to be binge eating (BE) [3], which refers to recurrently consuming unusually large amounts of food in one siting while simultaneously feeling a loss of control, often resulting in significant distress [4]. BE is one of the core symptoms of binge eating disorder [4].

In the general population, binge eating disorder is associated with significant medical morbidity, including sleep problems, chronic pain, dyslipidemias, and metabolic and cardiac dysfunction [5, 6]. BE also increases risk for poorer micronutrient intake, as binge episodes typically involve consumption of foods high in sugar, fat, and salt $[7,8]$. Frequent consumption of such foods and in large quantities can cause spikes in blood glucose [9] and research indicates that $\mathrm{BE}$ is linked prospectively with both type 2 diabetes and metabolic syndrome [10, 11]. Additionally, binge eating disorder is associated with higher levels of disability, psychosocial stress, and poorer quality of life $[5,6]$. Importantly, BE also is closely associated with obesity and depression [12], which can amplify existing medical morbidities common among older adults. In older women, the health consequences of any form of disordered eating may be even more severe than seen in the general population, as older women have pre-existing risk for nutritional disorders (both over- and under-nutrition), sarcopenia, and frailty [13]. Despite this, older women historically have been excluded from $\mathrm{BE}$ research, leaving a major gap in understanding the risk, maintenance, and health consequences of $\mathrm{BE}$ among older women.

Eating disorder researchers have historically paid scant attention to older women. Despite this lack of research, numerous aging-related factors may contribute to elevating risk for BE in this population. Specifically, experiences related to the menopausal transition comprise risk for BE $[3,14]$. For instance, a recent pilot study found that elevated daily estradiol, when progesterone was also elevated, was associated with $\mathrm{BE}$ episodes in perimenopausal women [14]. Sleep disturbances and negative affect, both of which are common experiences of women during the menopausal transition [15], also are well-established risk factors for $\mathrm{BE}[16,17]$. Additionally, psychosocial stressors, such as caregiving demands and interpersonal strain, may increase further risk for dysregulated eating behaviors, especially for women [18]. Indeed, preliminary research suggests that older women who experience life stressors such as divorce, marital conflicts, traumatic illness, empty nest syndrome, and loss of parents, siblings or children are at increased risk for onset of disordered eating [19].

Additionally, aging-related changes in body shape/ appearance (e.g., increased adipose tissue, decreased muscle mass, increased body fat distribution towards the torso, and changes in skin coloration, firmness, and elasticity; [20-22] may also increase risk for disordered eating $[3,23]$. These changes shift women's bodies further away from the thin-young-ideal standard of female beauty in Western societies. This increased deviation from societal standards of female beauty, in turn, further increases risk for harmful comparisons of self to media representations and/or one's younger body weight or shape [24]. Such upward body comparisons often lead to or exacerbate negative body image (also referred to as body dissatisfaction), which is a well-established and robust risk factor for BE [25].

Notably, recent research indicates that older women experience high levels of body dissatisfaction. For instance, Mangweth-Matzek et al. [2] found that over $60 \%$ of women age $60-70$ years endorsed body dissatisfaction. Kilpela et al. [26] found that negative body image mediated the relation between BMI and both health/ wellness behaviors as well as quality of life among women aged 50 and over. Thus, negative body image appears to be prevalent among older women and increase risk for both disordered eating and poorer health outcomes. In sum, early research investigating prevalence rates of $\mathrm{BE}$ among older women indicate that this pathology is more pervasive than previously thought. Yet, given that the aging process poses unique risk for women with regards to $\mathrm{BE}$, there is still much to learn about both prevalence and health correlates of $\mathrm{BE}$ among older women.

As noted above, the intersection of aging and eating disorders is an emerging field of research. When broaching a new area of science, it is important that researchers are accountable and present well-informed findings, specifically when researching populations not often represented in research. The replication of research findings is one way to increase accountability, especially when presenting research findings in emerging domains.

Indeed, recent literature has documented a "replication crisis" in psychological science highlighting the importance of replicating findings in independent studies [27]. In their seminal paper, Open Science Collaboration set out to replicate 100 experiments; only $36 \%$ yielded a 
statistically significant effect in the replication effort. This outcome signaled a concerning lack of replication and raised significant questions regarding the validity of the original findings. In response to rising concerns about replication in psychological science and the paper by the Open Science Collaboration, Lindsay and editors at Psychological Science [28] identified three factors (referred to as the "troubling trio") that appeared to contribute to lack of replication. These factors are, in terms coined by Lindsay: (1) "low statistical power," (2) "a surprising finding," and (3) "a $p$ value of only slightly less than $p=0.05$ " [28]. According to Lindsay [28], any research findings that meet one or more of these criteria warrant efforts for replication.

\section{The present research}

The original purpose of this research was to examine the prevalence of $\mathrm{BE}$ and health correlates in older women in a single study. However, the primary finding of this original study (hereafter referred to as the index study) met Lindsay's criterion of a "surprising finding," which is one of the "troubling trio" [28]. Specifically, the prevalence rate of weekly $\mathrm{BE}$ in the index study was higher than those seen in the limited existing research (e.g., [1-3]). This raised the specter of a spurious finding which led to the development of three specific aims for a series of studies presented in this paper. First, we sought to describe the frequency of binge eating in older women. Per DSM-5 diagnostic criteria for bulimia nervosa and binge eating disorder [4], which require binge eating once per week on average, we used the frequency criterion of weekly or more $\mathrm{BE}$ in our descriptions of prevalence rates within each sample. Second, we sought to identify the health behaviors correlated with binge eating in older women. Finally, we sought to determine if findings from the index study would replicate by comparing the findings of two additional samples of older women.

\section{Method}

\section{Index study: general online sample of women}

\section{Participants}

Participants were 185 women recruited online. Participants ranged from 60 to 83 years of age $(M=65.91$, $S D=5.09$ ); $86.4 \%$ identified as White and $2.2 \%$ endorsed Hispanic/Latina ethnicity (Table 1). Over one-third of participants (36.4\%) reported a body mass index (BMI) greater than 30 (i.e., obese status), while $23.2 \%$ reported a $\mathrm{BMI}$ in the overweight range (25-29.9).

\section{Procedure}

The Institutional Review Board (IRB) of the senior author's institution deemed this study as IRB-exempt (i.e., no more than minimal risk to study participants).
Participants were recruited via email using personal and professional networks (i.e., non-randomized snowball sampling) and Amazon Mechanical Turk within the United States. We recruited women, aged 60 and over, to complete an online survey on health and wellness among older women. After providing informed consent, participants completed self-report questionnaires online.

\section{Measures \\ Demographic information}

Participants reported age, height, weight, race and ethnicity. Although self-report is not optimal for assessing height and weight, research indicates that self-report weights are reasonably accurate [29] and we were limited to self-report due to the online nature of the study.

\section{Binge eating}

As our primary measure of $\mathrm{BE}$, we used the VA-Binge Eating Screener (VA-BES; [30]), which asks: "On average, how often have you eaten extremely large amounts of food at one time and felt that your eating was out of control at that time?" Response options include: Never, $<1$ time/week, 1 time/week, 2-4 times/week, and 5+times/ week. This measure demonstrated good psychometric properties [30].

\section{Eating disorder (ED) symptoms}

We assessed ED symptoms using the Eating Disorder Examination Questionnaire (EDE-Q Short; [31]), which is a 12-item version of the full EDE-Q [32]. The EDE-Q Short measures ED symptoms over the past week, using a $0-3$ scale ranging from 0 to 7 days in the past week. Within this measure, one item asks about number of $\mathrm{BE}$ episodes in the past week. We did not isolate this item for any inferential statistics; however, we used selfreported BE frequency on this measure as an indicator of convergent validity participant responses to the primary measure of BE frequency (i.e., the VA-BES) to evaluate consistency of reporting. Past research demonstrated good internal consistency (Cronbach's $\alpha=0.913$ ) and temporal stability $(\mathrm{ICC}=0.93 ; p<0.001 ;[31])$. Internal consistency in the current sample was good $(\alpha=0.86)$.

\section{Negative affect}

We used the 17-items of the fear, guilt and sadness subscales of the Positive and Negative Affect Scale-revised (PANAS-X; [33]) to measure negative affect over the past 3 weeks; higher scores indicate greater negative affect. This subscale has demonstrated good internal consistency in past research (current sample $\alpha=0.95$ ). 
Table 1 Participant demographics and descriptive statistics for all three samples

\begin{tabular}{|c|c|c|c|}
\hline & $\begin{array}{l}\text { Study } 1(N=185) \\
\% \text { or } M(S D)\end{array}$ & $\begin{array}{l}\text { Study } 2(N=64) \\
\%\end{array}$ & $\begin{array}{l}\text { Study } 3(N=100) \\
\% \text { or } M(\mathrm{SD})\end{array}$ \\
\hline Age & $65.91(5.09)$ & $\begin{array}{l}84.4 \% \text { (Age 66-75) } \\
15.6 \% \text { (Age } 76+\text { ) }\end{array}$ & $60.57(5.05)$ \\
\hline \multicolumn{4}{|l|}{ Race/Ethnicity } \\
\hline Black & $9.2 \%$ & $15.9 \%$ & $16.8 \%$ \\
\hline White & $86.4 \%$ & $14.3 \%$ & $72.0 \%$ \\
\hline Hispanic/Latinx & $2.2 \%$ & $65.1 \%$ & $2.0 \%$ \\
\hline Other/mixed & $4.3 \%$ & $4.8 \%$ & $9.0 \%$ \\
\hline \multicolumn{4}{|l|}{ Level of education } \\
\hline Grade school or less & - & $32.9 \%$ & $0.0 \%$ \\
\hline Some high school & - & $15.6 \%$ & $0.0 \%$ \\
\hline High school diploma/GED & - & $26.6 \%$ & $5.0 \%$ \\
\hline Some college/technical school & - & $23.4 \%$ & $16.8 \%$ \\
\hline Bachelor's degree & - & $1.6 \%$ & $18.8 \%$ \\
\hline Some graduate school & - & $0.0 \%$ & $9.9 \%$ \\
\hline Master's degree & - & $0.0 \%$ & $34.7 \%$ \\
\hline Doctoral degree & - & $0.0 \%$ & $14.9 \%$ \\
\hline \multicolumn{4}{|l|}{ Annual household income } \\
\hline Under $\$ 10,000$ & - & $46.9 \%$ & - \\
\hline$\$ 10,000-\$ 40,000$ & - & $37.5 \%$ & - \\
\hline$\$ 40,000-\$ 65,000$ & - & $3.1 \%$ & - \\
\hline BMI & $28.29(7.71)$ & - & $26.62(6.04)$ \\
\hline Binge eating & $26.5 \%$ & $20.4 \%$ & $19.0 \%$ \\
\hline \multicolumn{4}{|l|}{ Compensatory behaviors } \\
\hline Driven exercising & $8.7 \%^{\mathrm{a}}$ & $12.6 \%^{\mathrm{b}}$ & $13.9 \%^{b}$ \\
\hline Self-induced vomiting & $2.7 \%^{\mathrm{a}}$ & $7.9 \%^{\mathrm{b}}$ & $1.0 \%^{\mathrm{b}}$ \\
\hline Laxatives or diuretics & $2.7 \%^{\mathrm{a}}$ & $11.0 \%^{\mathrm{b}}$ & $3.0 \%^{\mathrm{b}}$ \\
\hline
\end{tabular}

Study 1 = General online sample; Study 2 =Women living with food insecurity; Study $3=$ Women with high education levels; BMI = Body mass index; Binge Eating $=$ binge eating at a frequency of weekly or more; Compensatory behaviors = behaviors endorsed for the purpose of weight/shape control

${ }^{\mathrm{a}}=$ Endorsed this behavior in the past week

$\mathrm{b}=$ Endorsed this behavior in the past month

\section{Consumption of nutritious foods}

The two-item Eating Behaviors Questionnaire (EBQ; [34]) measured self-reported consumption of nutritious foods. Items inquire how often participants consciously tried to increase micronutrient density in meals and frequency of consuming fresh fruits and vegetables over the past week. The EBQ uses a 5 -point Likert scale $(1=$ consume at every meal, $5=$ never); items are summed, and higher scores indicate less consumption of nutritious foods. Internal consistency in this sample was adequate $(\alpha=0.63)$.

\section{Results}

We used descriptive statistics to evaluate BE prevalence and frequency in this sample. Due to the ordinal nature of BE frequency measure, we used Spearman's rho to investigate correlations of $\mathrm{BE}$ frequency with BMI, ED symptoms, negative affect, and consumption of nutritious foods. Finally, we used a binomial logistic regression model to investigate the degree to which $\mathrm{BE}$ frequency contributed to risk for obesity status while controlling for age, race, and ethnicity. Regarding $\mathrm{BE}$ frequency and prevalence (Table 1 ), $48 \%$ of the sample reported never $B E$. Using the clinical frequency criterion of $\mathrm{BE}$ once per week or more, $26.5 \%$ of the sample reported $\mathrm{BE}$ at least weekly. As a secondary measure of $\mathrm{BE}$ frequency in this sample, we examined rates of $\mathrm{BE}$ using the BE item on the EDE-Q Short. One participant's answer did not align with their response on the VA-BES, resulting in $25.5 \%$ of the sample endorsing at least one $\mathrm{BE}$ episode in the past week. BE frequency was correlated with higher BMI $(\rho=0.40, p<0.01)$, more ED symptoms $(\rho=0.65, p<0.001)$, greater negative affect $(\rho=0.43, p<0.01)$, and less frequent consumption of nutritious foods $(\rho=0.16, p<0.05)$. Finally, $\mathrm{BE}$ frequency contributed significant risk for obese 
status based on self-reported BMI $(O R=2.08 ; 95 \% \mathrm{CI}$ $[1.52 ; 2.82], p<0.001)$. Age, race, and ethnicity categories were non-significant in the model.

\section{Study 2 (replication): sample living with food insecurity Participants}

This sample consisted of 64 older women (ages 66+) who were clients at food pantries of the local food bank who participated in a larger study of individuals living with food insecurity [35]. Age was only captured in clusters; thus, only women who selected the "age 66 or over" option were included in this study. Younger participants and men were not included. The majority of participants identified as Hispanic (65.1\%; Table 1). Over a third (39.1\%) reported disabled status, and $48.4 \%$ had less than a high school education or equivalent (GED). Almost half (46.9\%) reported a household annual income of less than $\$ 10,000 /$ year. Access to current health data is often low among individuals living with extreme poverty; scales are considered luxury items and often are not in the home [35]. Thus, requesting current height and weight in this sample was likely to elicit inaccurate data. Therefore, we do not have BMI data in this sample.

\section{Procedure}

This study received IRB approval and was run in collaboration with the local food bank. See Becker et al. [35] for details regarding the full study and community partnership. All questionnaires were available in either English or Spanish. Following informed consent, participants completed questionnaires in person; undergraduate research assistants facilitated reading as needed (i.e., read questions aloud in language of choice) and answered questions. Participants received a $\$ 5$ gift card to a local grocery store as compensation.

\section{Measures}

Consistent with working with a marginalized, low-education population and incorporating a socially conscious lens [36, 37], we evaluated survey complexity. Guided by a colleague with extensive experience working with marginalized populations, we employed best practices delineated by Stonewall and colleagues [38] to evaluate and modify questionnaire language. We modified or removed items based on reading level or that may impact comprehension (for detailed rationale and procedure for measures modification, see Becker et al. [35]). This process ensured that our survey used appropriate language in order to be inclusive and culturally sensitive [36].

\section{Food insecurity}

To assess severity of food insecurity, we used the Radimer Cornell Food Insecurity Measure (RCFIM: [39, 40]).
This measure uses a Likert scale, and global scores indicate level of food insecurity: (1) not food insecure (i.e., did not meet criteria for food. insecurity); (2) household food insecurity (i.e., anxiety about food, eating the same thing repeatedly due to lack of resources, and food running out but no one going hungry in the home); (3) individual food insecurity (i.e., adult reports being hungry at times because they lack food); and (4) child hunger food insecurity (i.e., adult reports inability to adequately feed their children secondary to lack of resources). For this study, we only included participants in the two highest levels of food insecurity (individual and child hunger), as these are the most severe. Internal consistency was good in our sample (Cronbach's $\alpha=0.92$ ).

\section{Binge eating}

We used the BE item from the Eating Disorder Diagnostic Scale for DSM 5 (EDDS-5) to assess frequency of BE over the past month [41]. The EDDS is a brief self-report measure designed to assess the spectrum of EDs. The $\mathrm{BE}$ item asks, "How many times in the past month (3031 days) on average have you eaten an unusually large amount of food and experienced a loss of control?" A report of $\geq 4$ times in the past month equated to weekly binge eating.

\section{Internalized weight stigma}

We used the Weight Self-Stigma Questionnaire (WSSQ) to assess internalization of weight bias [42]. Items are rated on a 7 - point Likert scale $(1=$ strongly disagree to $7=$ strongly agree), and participants rate their level of agreement with explicit weight bias statements (e.g., "I became fat because I'm a weak person" and "People think that I am to blame for being fat."). Scores are summed for a total score and higher scores indicate greater selfstigma; internal consistency was excellent $(\alpha=0.97)$.

\section{Anxiety}

We used eight items from the Penn State Worry Questionnaire (PSWQ; [43]) to assess anxiety/worry. Items are rated on a 5-point Likert scale $(1=n o t$ at all typical of $m e$ to $5=$ very typical of $m e$ ); higher scores indicate more anxiety/worry. Internal consistency for this version of the PSWQ in the current sample was excellent $(\alpha=0.95)$.

\section{Results}

Similar to the index study, we used descriptive statistics to evaluate $\mathrm{BE}$ prevalence and frequency in this replication sample. We used bivariate correlations of $\mathrm{BE}$ frequency with anxiety and internalized weight stigma. Finally, we examined rates of unhealthy weight control behaviors (e.g., self-induced vomiting, use of laxatives/ diuretics for weight control) in this sample. Regarding 
BE prevalence, $20.4 \%$ of this sample reported $B E$ on a weekly or more basis in the past month. Frequency of BE was positively correlated with higher anxiety $(r=0.37$, $p=0.008)$ and internalized weight stigma ( $r=0.42$, $p=0.002$ ). Within this sample of older women living with significant food insecurity, $7.9 \%$ of women reported selfinduced vomiting, and $11 \%$ reported use of laxative or diuretics for weight control in the past month.

\section{Study 3 (replication): sample with high education levels Participants}

Participants were 100 women recruited online for a larger study of body image in a diverse sample of adult women. Participant ages ranged from 55-79 years $(M=60.57$, $S D=5.05)$ and reported a mean body mass index of 26.62 $(S D=6.04)$. The majority $(72.0 \%)$ self-identified as White; $2.0 \%$ identified as Hispanic/Latina, and $72 \%$ were currently married (Table 1). Notably, $50 \%$ of women in this sample had a Masters or Doctoral degree.

\section{Procedure}

IRB approval was granted for this study and participants were recruited via email, social media, personal and professional networks, and by word of mouth. Recruitment emails described the study as exploring body image and wellness in a diverse population of adult women. All emails and posts requested that women forward the study invitation to their own social and professional networks (i.e., snowball sampling). After providing informed consent, participants completed self-report questionnaires online and had the option to provide their email address to enter a raffle for a \$200 Amazon gift card.

\section{Measures \\ Binge eating}

We assessed BE with the diagnostic items of the EDE-Q [32], which is a self-report measure of eating behaviors and attitudes over the past 28 days. The BE items inquire about frequency of BE episodes over the past 28 days. A report of $\geq 4$ times in the past four weeks (28 days) equated to weekly BE.

\section{BMI}

Participants self-reported their height and weight in order to calculate BMI.

\section{Depressive symptoms}

We used the Beck Depression Inventory- II (BDI-II; [44]) to measure depressive symptoms. Due to liability in assessing suicidality anonymously and via online survey, we removed the suicidality item from the BDI-II. Thus, our final measure included 20 items and had good internal validity in the current sample $(\alpha=0.85)$.

\section{Body shame}

We administered the Shame subscale of the Objectified Body Consciousness Scale (OBCS; [45]). This subscale includes eight items rated from 1 (strongly disagree) to 7 (strongly agree), with a "not applicable" option for items that do not apply. Higher scores indicate greater shame, and $25 \%$ or more of items NA or missing qualifies as missing overall score. In the present sample, internal consistency was good $(\alpha=0.85)$.

\section{Results}

Similar to the previous studies, we used descriptive statistics to evaluate BE prevalence and frequency in this second replication sample. We used bivariate correlations of $\mathrm{BE}$ frequency with BMI, depressive symptoms, and body shame. Finally, we used a binomial logistic regression model to investigate the degree to which BE frequency contributed to risk for obesity status while controlling for age, race, and ethnicity. In this sample of women with high education levels, $19 \%$ reported BE weekly or more in the past month. BE frequency was positively correlated with greater depressive symptoms $(r=0.36, p<0.001)$ and higher body shame $(r=0.44, p<0.001)$, but was not correlated with BMI $(r=0.20, p=0.075)$. Finally, BE frequency contributed a small, but statistically significant risk for obesity status $(O R=1.12 ; 95 \%$ CI [1.00, 1.24], $p=0.04)$. Neither age nor race/ethnicity were significant in the model.

\section{Discussion}

The index study in this series of studies was designed to examine the frequency, prevalence, and health correlates of binge eating (BE) in a single sample of older women aged 60 and over. Findings from this index study indicated that roughly $26 \%$ of older women in our sample reported experiencing $\mathrm{BE}$ at a frequency of weekly or more in the past month. Notably, the clinical frequency criterion for a diagnosis of binge eating disorder or bulimia nervosa is BE weekly or more for at least 3 months [4]. Prior research, however, identified lower prevalence rates of weekly BE among midlife and older adult women. For instance, $11 \%$ of women in midlife reported regular $\mathrm{BE}$ as assessed by self-report with the Bulimia Test-Revised (BULIT-R; [12]). Using a non-validated self-report measure inquiring about frequency of BE episodes, $3.5 \%$ of women aged $50+$ reported weekly BE [46]. Using a similar assessment measure, a sample of women aged $60-70$ years, $3.8 \%$ met criteria for an ED, 
while another $4.4 \%$ endorsed at least one core symptom of an ED [2].

Notably, the vast majority of research examining prevalence rates and types of eating disordered behaviors among older adults used self-report measures, rather than gold standard clinical interviews (e.g., the Eating Disorders Examination; [47]). In one study that utilized a structured clinical interview, 5.6\% of women aged 65-94 reported $\mathrm{BE}$ episodes in the past month, with mean frequency of 8 episodes/month [1]. Thus, prevalence rates of disordered eating documented in the literature ranged from roughly $4-11 \%$ and are smaller than our findings.

Of note, $59.6 \%$ of participants in the index study met BMI classification criteria for overweight (i.e., $25<\mathrm{BMI}<30$ ) or obese status (i.e., BMI $>30$ ). To put this in context, past research investigating $B E$ prevalence in obese patients presenting for weight loss treatment has documented clinically relevant BE at approximately $30 \%$ [48-50]. Thus, our observed prevalence rate for weekly $\mathrm{BE}$ in the index study was slightly lower than data from general adult patients (i.e., not older adults) presenting for weight loss programs. Our sample was neither a treatment-seeking sample, nor did we conduct targeted recruitment for clinical populations. Thus, the higher prevalence of overweight/obesity may have played a role in the elevated rates of $\mathrm{BE}$ in this first sample, as compared to past research and to the other two studies.

Because the prevalence rate of weekly or more $\mathrm{BE}$ from this index study was surprisingly high (i.e., a "surprising finding" per Lindsay; [28]), we were concerned about a spurious finding. Specifically, our findings fell into one construct of the "troubling trio" [28] in the replication crisis in psychological science, which raised concerns regarding replicability. Per recommendations from Lindsay [28], such results warrant efforts for replication. Therefore, we sought to replicate our index study results using existing data from two other samples of older adult women that included self-reported BE frequency. Results from both replications using data from two additional independent studies - with notably different demographics-were largely consistent with the index study.

We propose that the combined results suggest that $\mathrm{BE}$ rates in older women may be higher than previously thought and are deserving of further research. While these data do not examine the full diagnostic criteria for binge eating disorder, findings across the three studies provide preliminary data supporting the need for more research regarding eating disorders among older adults. The primary strength of the three studies, when viewed collectively, is the ability to refute the argument that the primary findings of the index study (i.e., BE prevalence and frequency) were artificially inflated due to one or more of the following three factors: (1) sampling biases secondary to recruitment strategy; (2) measurement error (i.e., risk of inherent response biases within one measure); and (3) participant demographics (i.e., limited generalizability). Regarding the first concern of sampling bias, two of the three studies used different types of internet sampling (i.e., snowball sampling, social media, and MTurk), whereas one used in-person recruitment and data collection. Despite the different sampling methods (internet versus in-person/community), prevalence rates of $\mathrm{BE}$ were similar across all three studies, suggesting the rates were not unique to one sampling method.

The second potential concern pertains to the way in which BE was assessed. For instance, it could be argued that the primary measurement strategy of the index study (i.e., the VA-BES) was flawed and resulted in inflated estimates of $B E$ in the index sample. However, we used a total of four validated measures of $\mathrm{BE}$ across the three studies and findings remained remarkably consistent. Therefore, our findings regarding prevalence rates of $\mathrm{BE}$ were not simply due to measurement error. Of note, prior research utilized both validated and non-validated selfreport instruments to assess rates of current binge eating among midlife and older women; only one study used a clinical interview.

Finally, one could argue, based on the index study alone, that the representativeness of the index sample in terms of sample characteristics (i.e., participant demographics) led to elevated assessment of BE. This supposition, however, does not appear to hold water when the nature of the three samples are compared. For instance, the community sample collected at local food pantries was predominantly Hispanic (65\%), predominantly very low SES (47\% reported an annual household income $<\$ 10,000 /$ year) and living with significant food insecurity. Moreover, nearly $50 \%$ reported less than a high school degree or equivalent, and nearly $40 \%$ reported disabled status. In contrast, both of the internet samples were majority Non-Hispanic White, and one internet sample comprised women with high levels of education (50\% Masters or Doctoral Degree). In summary, we found fairly consistent rates of self-reported BE at least weekly (19-26\%) across three independent and very different samples in terms of race/ethnicity, education, food security status, measurements used, and data collection methods.

In addition to a high prevalence rate of weekly $\mathrm{BE}$ across the three samples, correlational analyses indicated that BE frequency was related to poorer psychological and physical health indices. Specifically, higher BE frequency was positively correlated with greater depression and negative affect, body shame, worry, and internalized weight stigma. Additionally, BE frequency was negatively correlated with frequency of consuming nutrient-dense foods. Lastly, results regarding BMI were mixed across 
two samples. In our index study, BE frequency was positively correlated with BMI, while this relation was nonsignificant in the highly educated sample. However, in both samples BE frequency increased risk for obesity status in our binomial logistic regression models. Thus, further investigation into obesity risk as a factor $\mathrm{BE}$ among diverse samples of older women is warranted.

Correlational findings from these three studies align with previous research on correlates of $\mathrm{BE}$ in younger samples. For instance, BE is consistently linked with depressive symptoms [12] and elevated BMI [51, 52] in prior research. Our correlational findings in this sample of older women are consistent with $\mathrm{BE}$ correlates observed in previous $\mathrm{BE}$ research conducted with more well-investigated samples (i.e., younger adults). In other words, expected $\mathrm{BE}$ and health correlates previously established hold true in this newer population of older adult women, which provides confidence in our interpretation of these data. Finally, these data extend prior research by documenting additional negative health correlates (e.g., internalized weight stigma, worry, and consumption of nutritious foods) of $\mathrm{BE}$ in older adult women.

It is important to note that we did not assess the full criteria for a diagnosis of binge eating disorder, per the DSM-5 [4]. Although women across these three separate studies reported BE weekly, this was only assessed in the past month. Additionally, we did not collect information on the emotional/cognitive criteria for binge eating disorder; rather, we only assessed the frequency of the behavior in the past month. Therefore, these findings may reflect a lower level of BE pathology severity in comparison to clinical-level binge eating disorder. Alternatively, our data support the contention that regular BE, regardless of full diagnostic status, is associated with poorer health constructs (e.g., depression/negative affect, less frequent consumption of micronutrients, body shame, worry, internalized weight stigma). Future research is needed to disentangle the potential health impacts of $\mathrm{BE}$ behaviors versus clinical threshold binge eating disorder among older adult populations.

There are numerous limitations to the current studies. First, all studies used self-report measures exclusively. Thus, it is entirely possible that results from self-report measures showed a greater frequency of BE as compared to those assessed by structured clinical interview. Further, we did not have objective measures of BMI nor clinical interviews to further explore clinical constructs. Second, although the three studies used different sampling methods, two of the three studies comprised minimal racial/ ethnic diversity of participants and were online samples. Future research should use purposeful sampling methodology in order to evaluate more diverse samples of older adult women and therefore enhance generalizability of findings. Additionally, analyses were cross-sectional and correlative in nature, therefore we are unable to evaluate causality among variables within each study. Future research should include larger sample sizes, incorporate clinical interviews, and utilize longitudinal methodology designed to investigate causality and chronological outcomes. Lastly, future studies should assess the full diagnostic criteria for binge eating disorder, in order to better estimate the prevalence of this pathology among older adult women.

\section{Conclusions}

In sum, findings indicated relatively stable rates of weekly or more BE (19-26\%) among three independent and very different samples of older adult women. The rates observed across these three samples are higher than those documented in prior research and in younger samples, suggesting that older adult women may be at elevated risk for $\mathrm{BE}$, yet further research is needed to examine the full diagnostic criteria for binge eating disorder. Correlations indicated that BE frequency is linked with negative health constructs, including depression and negative affect, body shame, worry, and internalized weight stigma. Longitudinal research is needed to better investigate the chronological effects of $\mathrm{BE}$ among older adult samples, as well as objective or interview methods of data collection.

\section{Abbreviations}

BE: Binge eating; BMI: Body mass index; ED: Eating disorder; DSM-5: Diagnostic and Statistical Manual for Mental Disorders, 5th edition; IBR: Institutional Review Board; VA-BES: Veterans Affairs-Binge Eating Screener; EDE-Q: Eating Disorders Examination-Questionnaire; PANAS-X: Positive and Negative Affect Schedule; EBQ: Eating Behaviors Questionnaire; RCFIM: Radimer Cornell Food Insecurity Measure; EDDS-5: Eating Disorders Diagnostic Scale for DSM-5; WSSQ: Weight Self Stigma Questionnaire; PSWQ: Penn State Worry Questionnaire; BDI-II: Beck Depression Inventory-II; OBCS: Objectified Body Consciousness Scale; SES: Socioeconomic status.

\section{Acknowledgements}

The authors thank the San Antonio Food Bank and affiliated food pantries, as well as Dr. Keesha Middlemass and Ms. Christina Verzijl, for their contributions to this research.

\section{Authors' contributions}

SAW was involved in development, data collection, and data cleaning of Study 3. SAW also was instrumental in writing this manuscript. CBB was PI for Studies 2 and 3 (i.e., study conceptualization, data collection, data analyses), and she was instrumental in writing this manuscript. KEK helped with conceptualization and execution of Study 1 and editing of this manuscript. NM and SEE were both involved with conceptualization, measures selection, and data interpretation for Study 1. They also edited the manuscript. LSK was PI for Study 1 (i.e., conceptualization, data collection, data analyses), conceptualized the current manuscript, conducted data analyses for all three studies, and was instrumental in writing. All authors read and approved the final manuscript. 


\section{Funding}

This work was supported by funding from the National Institute on Aging (NIA) and the American Federation for Aging Research [K76AG060003-A1] and NIA [P30 AG044271].

\section{Availability of data and materials}

The datasets used and/or analyzed during the current study are available from the corresponding author on reasonable request.

\section{Declarations}

\section{Ethics approva}

Study 1 was deemed exempt by the UT Health San Antonio IRB (18-268E).

Studies 2 and 3 were approved by the Trinity University IRB.

\section{Consent for publication}

Not applicable.

\section{Competing interests}

The authors declare that they have no competing interests.

\section{Author details}

${ }^{1}$ Department of Psychology, University of Missouri-Kansas City, Kansas City, MO, USA. ${ }^{2}$ Department of Psychology, Trinity University, San Antonio, TX, USA. ${ }^{3}$ ReACH Center, UT Health San Antonio, San Antonio, TX, USA. ${ }^{4}$ Barshop Institute, UT Health San Antonio, San Antonio, TX, USA. ${ }^{5}$ South Texas VA Health System, Audie Murphy Veterans Hospital, San Antonio, TX, USA.

Received: 19 July 2021 Accepted: 22 September 2021 Published online: 19 October 2021

\section{References}

1. Conceicao EM, Gomes F, Vaz AR, Pinto-Bastos A, Machado PP. Prevalence of eating disorders and picking/nibbling in elderly women. Int J Eat Disord. 2017;50(7):793-800.

2. Mangweth-Matzek B, Rupp Cl, Hausmann A, Assmayr K, Mariacher E, Kemmler G, Whitworth AB, Biebl W. Never too old for eating disorders or body dissatisfaction: a community study of elderly women. Int J Eat Disord. 2006;39(7):583-6.

3. Mangweth-Matzek B, Hoek HW, Pope HG Jr. Pathological eating and body dissatisfaction in middle-aged and older women. Curr Opin Psychiatry. 2014;27(6):431-5.

4. American Psychiatric Association. Diagnostic and statistical manual of mental disorders (DSM-5 $\left.{ }^{\circledR}\right)$. American Psychiatric Pub; 2013.

5. Johnson JG, Spitzer RL, Williams JB. Health problems, impairment and illnesses associated with bulimia nervosa and binge eating disorder among primary care and obstetric gynaecology patients. Psychol Med. 2001;31(8):1455-66.

6. Olguin P, Fuentes M, Gabler G, Guerdjikova Al, Keck PE, McElroy SL. Medical comorbidity of binge eating disorder. Eat Weight Disord. 2017;22(1):13-26.

7. Avena NM, Rada P, Hoebel BG. Sugar and fat bingeing have notable differences in addictive-like behavior. J Nutr. 2009;139(3):623-8.

8. Masheb RM, Dorflinger LM, Rolls BJ, Mitchell DC, Grilo CM. Binge abstinence is associated with reduced energy intake after treatment in patients with binge eating disorder and obesity. Obesity. 2016;24(12):2491-6.

9. Mitchell JE, King WC, Pories W, Wolfe B, Flum DR, Spaniolas K, Bessler M, Devlin M, Marcus MD, Kalarchian M, Engel S. Binge eating disorder and medical comorbidities in bariatric surgery candidates. Int J Eat Disord. 2015;48(5):471-6.

10. Mitchell JE. Medical comorbidity and medical complications associated with binge-eating disorder. Int J Eat Disord. 2016;49(3):319-23.

11. Thornton LM, Watson HJ, Jangmo A, Welch E, Wiklund C, von HausswolffJuhlin Y, Norring C, Herman BK, Larsson H, Bulik CM. Binge-eating disorder in the Swedish national registers: somatic comorbidity. Int J Eat Disord. 2017;50(1):58-65.
12. Marcus MD, Bromberger JT, Wei HL, Brown C, Kravitz HM. Prevalence and selected correlates of eating disorder symptoms among a multiethnic community sample of midlife women. Ann Behav Med. 2007;33(3):269-77.

13. Chapman IM. Nutritional disorders in the elderly. Med Clin. 2006;90(5):887-907.

14. Baker JH, Eisenlohr-Moul T, Wu YK, Schiller CE, Bulik CM, Girdler SS. Ovarian hormones influence eating disorder symptom variability during the menopause transition: a pilot study. Eat Behav. 2019;35:101337.

15. Bromberger JT, Matthews KA, Schott LL, Brockwell S, Avis NE, Kravitz HM, Everson-Rose SA, Gold EB, Sowers M, Randolph JF Jr. Depressive symptoms during the menopausal transition: the Study of Women's Health Across the Nation (SWAN). J Affect Disord. 2007;103(1-3):267-72.

16. Dingemans A, Danner U, Parks M. Emotion regulation in binge eating disorder: a review. Nutrients. 2017;9(11):1274.

17. Cerolini S, Ballesio A, Ferlazzo F, Lucidi F, Lombardo C. Decreased inhibitory control after partial sleep deprivation in individuals reporting binge eating: preliminary findings. PeerJ. 2020;8:e9252.

18. Koumoutzis A, Cichy KE. What's eating you? Risk factors for poor health behaviors among family caregivers. Aging Ment Health. 2020. https://doi. org/10.1080/13607863.2020.1805722.

19. Kally Z, Cumella EJ. 100 midlife women with eating disorders: a phenomenological analysis of etiology. J Gen Psychol. 2008;135(4):359-78.

20. Evans WJ, Lexell J. Human aging, muscle mass, and fiber type composition. J Gerontol A Biol Sci Med Sci. 1995;50(Special_Issue):11-6.

21. Šitum M, Buljan M, Čavka V, Bulat V, Krolo I, Lugović ML. Skin changes in the elderly people-how strong is the influence of the UV radiation on skin aging? Coll Antropol. 2010;34(2):9-13.

22. Tchkonia T, Morbeck DE, Von Zglinicki T, Van Deursen J, Lustgarten J, Scrable H, Khosla S, Jensen MD, Kirkland JL. Fat tissue, aging, and cellular senescence. Aging Cell. 2010;9(5):667-84.

23. Gupta MA. Concerns about aging skin and eating disorders. In: Strumia R, editor. Eating disorders and the skin. Berlin: Springer; 2013. p. 97-102.

24. Peat CM, Peyerl NL, Muehlenkamp JJ. Body image and eating disorders in older adults: a review. J Gen Psychol. 2008;135(4):343-58.

25. Stice E. Risk and maintenance factors for eating pathology: a meta-analytic review. Psychol Bull. 2002;128(5):825-48.

26. Kilpela LS, Verzijl CL, Becker CB. Body image in older women: a mediator of BMI and wellness behaviors. J Women Aging. 2021;33(3):298-311.

27. Anderson JE, Aarts AA, Anderson CJ, Attridge PR, Attwood A, Axt J, Babel M, Bahník Š, Baranski E, Barnett-Cowan M, Bartmess E. Estimating the reproducibility of psychological science. Science. 2015;349(6251):1-8. https://doi.org/10.1126/science.aac4716.

28. Lindsay DS. Replication in psychological science. Psychol Sci. 2015;26(12):1827-32

29. Stunkard AJ, Albaum JM. The accuracy of self-reported weights. Am J Clin Nutr. 1981;34(8):1593-9.

30. Dorflinger LM, Ruser CB, Masheb RM. A brief screening measure for binge eating in primary care. Eat Behav. 2017;26:163-6.

31. Gideon N, Hawkes N, Mond J, Saunders R, Tchanturia K, Serpell L. Development and psychometric validation of the EDE-QS, a 12 item short form of the Eating Disorder Examination Questionnaire (EDE-Q). PLoS ONE. 2016;11(5):e0152744

32. Fairburn CG, Beglin SJ. Eating disorder examination questionnaire. In: Cognitive behavior therapy and eating disorders. 2008. p. 309-13.

33. Crawford JR, Henry JD. The Positive and Negative Affect Schedule (PANAS): Construct validity, measurement properties and normative data in a large non-clinical sample. Br J Clin Psychol. 2004;43(3):245-65.

34. Becker CB, Verzijl CL, Kilpela LS, Wilfred SA, Stewart T. Body image in adult women: associations with health behaviors, quality of life, and functional impairment. J Health Psychol. 2019;24(11):1536-47.

35. Becker CB, Middlemass K, Taylor B, Johnson C, Gomez F. Food insecurity and eating disorder pathology. Int J Eat Disord. 2017;50(9):1031-40.

36. Belone L, Lucero JE, Duran B, Tafoya G, Baker EA, Chan D, Chang C, Greene-Moton E, Kelley MA, Wallerstein N. Community-based participatory research conceptual model: community partner consultation and face validity. Qual Health Res. 2016;26(1):117-35.

37. Snow ME, Tweedie K, Pederson A. Heard and valued: the development of a model to meaningfully engage marginalized populations in health services planning. BMC Health Serv Res. 2018;18(1):1-3. 
38. Roscoe RD, Chiou EK, Wooldridge AR, editors. Advancing diversity, inclusion, and social justice through human systems engineering. Boca Raton: CRC Press; 2019.

39. Kendall A, Olson CM, Frongillo EA Jr. Validation of the Radimer/Cornell measures of hunger and food insecurity. J Nutr. 1995;125(11):2793-801.

40. Radimer KL, Olson CM, Greene JC, Campbell CC, Habicht JP. Understanding hunger and developing indicators to assess it in women and children. J Nutr Educ. 1992;24(1):36S-44S.

41. Stice E, Fisher M, Martinez E. Eating disorder diagnostic scale: additional evidence of reliability and validity. Psychol Assess. 2004;16(1):60.

42. Lillis J, Luoma JB, Levin ME, Hayes SC. Measuring weight self-stigma: the weight self-stigma questionnaire. Obesity. 2010;18(5):971-6.

43. Meyer TJ, Miller ML, Metzger RL, Borkovec TD. Development and validation of the penn state worry questionnaire. Behav Res Ther. 1990;28(6):487-95.

44. Beck AT, Steer RA, Brown GK. Manual for the beck depression inventory-II.

45. McKinley NM, Hyde JS. The objectified body consciousness scale: development and validation. Psychol Women Q. 1996;20(2):181-215.

46. Gagne DA, Von Holle A, Brownley KA, Runfola CD, Hofmeier S, Branch KE, Bulik CM. Eating disorder symptoms and weight and shape concerns in a large web-based convenience sample of women ages 50 and above: results of the gender and body image (GABI) study. Int J Eat Disord. 2012;45(7):832-44.

47. Cooper Z, Fairburn C. The eating disorder examination: a semi-structured interview for the assessment of the specific psychopathology of eating disorders. Int J Eat Disord. 1987;6(1):1-8.
48. Dymek MP, le Grange D, Neven K, Alverdy J. Quality of life and psychosocial adjustment in patients after Roux-en-Y gastric report bypass: a brief report. Obes Surg. 2001;11(1):32-9.

49. Pagoto S, Bodenlos JS, Kantor L, Gitkind M, Curtin C, Ma Y. Association of major depression and binge eating disorder with weight loss in a clinical setting. Obesity. 2007;15(11):2557-9.

50. Conti C, Di Francesco G, Lanzara R, Severo M, Fumagalli L, Guagnano MT, Porcelli P. Alexithymia and binge eating in obese outpatients who are starting a weight-loss program: a structural equation analysis. Eur Eat Dis Rev. 2019;27(6):628-40.

51. Hudson Jl, Hiripi E, Pope HG Jr, Kessler RC. The prevalence and correlates of eating disorders in the National Comorbidity Survey Replication. Biol Psychiatry. 2007;61(3):348-58.

52. Udo T, Grilo CM. Prevalence and correlates of DSM-5-defined eating disorders in a nationally representative sample of US adults. Biol Psychiatry. 2018;84(5):345-54.

\section{Publisher's Note}

Springer Nature remains neutral with regard to jurisdictional claims in published maps and institutional affiliations.
Ready to submit your research? Choose BMC and benefit from:

- fast, convenient online submission

- thorough peer review by experienced researchers in your field

- rapid publication on acceptance

- support for research data, including large and complex data types

- gold Open Access which fosters wider collaboration and increased citations

- maximum visibility for your research: over $100 \mathrm{M}$ website views per year

At BMC, research is always in progress.

Learn more biomedcentral.com/submissions 